\title{
Addendum: A reproducible and well-tolerated method for 2/3 partial hepatectomy in mice
}

\author{
Claudia Mitchell \& Holger Willenbring
}

Nat. Protoc. 3, 1167-1170 (2008); published online 19 June 2008; addendum published after print 23 May 2014

In this addendum we provide an update to the part of our protocol 'A reproducible and well-tolerated method for $2 / 3$ partial hepatectomy in mice' that is related to analgesia ${ }^{1}$. Since the publication of this protocol in 2008 , researchers' awareness of and commitment to reducing postsurgical pain in mice have increased markedly, and the use of analgesics should now be the norm. In addition, experimental data are now available about efficacy and toxicity of analgesics in mice subjected to $2 / 3$ partial hepatectomy $(2 / 3 \mathrm{PH})^{2}$. Below we provide modifications to be made to the procedure to achieve effective analgesia without aggravating liver injury in mice undergoing 2/3 PH. In addition, we reiterate and extend our recommendations regarding choice of anesthetic and control of body temperature.

\section{Additional materials required}

- Buprenorphine hydrochloride (e.g., Buprenex, Reckitt Benckiser Pharmaceuticals, NDC no. 12496-0757-1)! CAUTION Because buprenorphine hydrochloride is a controlled substance, governmental authorization, e.g., by the Drug Enforcement Agency in the United States, and safe storage and record keeping are required.

- Bupivacaine hydrochloride 0.25\% (wt/vol) solution (e.g., bupivacaine HCl, Hospira, NDC no. 0409-1159-01)

- Warming system (e.g., warm water recirculator T/Pump (Gaymar, cat. no. TP700), with Mul.T.Pad (Gaymar, cat. no. TP22E))

- Body temperature monitoring system (e.g., Physitemp Instruments, TH-5 thermometer with RET-3 rectal probe for mice)

\section{Changes to the previously published PROCEDURE}

Steps 1-14: To prevent hypothermia in the mice under anesthesia, place the mice on a warming pad throughout the surgery. Use a regulatable warming system and body temperature monitoring (e.g., with a rectal probe) to prevent not only hypothermia but also hyperthermia ${ }^{3}$. Continue warming until the mice resume physical activity.

Step 1: Use only inhalant anesthetics such as isoflurane. The use of injectable anesthetics such as tribromoethanol (Avertin) or ketamine/xylazine is not recommended because of risk of insufficient anesthesia and severe side effects, including hepatotoxicity ${ }^{1}$. After anesthesia is induced, subcutaneously inject $0.1 \mathrm{mg} / \mathrm{kg}$ of the opioid buprenorphine hydrochloride. Step 13: After closing the abdominal muscles and peritoneum, and before closing the skin, place a drop of the local anesthetic bupivacaine hydrochloride $0.25 \%$ (wt/vol) solution ( $8 \mathrm{mg} / \mathrm{kg}$ maximum dose) on top of the incision ${ }^{4}$.

After Step 14: After completion of the PROCEDURE as described, maintain analgesia by subcutaneously injecting $0.1 \mathrm{mg} / \mathrm{kg}$ buprenorphine hydrochloride 4-6 $\mathrm{h}$ after the initial injection, and then every 8-12 $\mathrm{h}$ until the end of postoperative day 2 . To assess the adequacy of analgesia and the potential need for its extension, use an appropriate method to monitor mice for signs of pain throughout the postoperative period until the end of postoperative day 3 (ref. 5). Consider reducing the buprenorphine hydrochloride dose to $0.05 \mathrm{mg} / \mathrm{kg}$ in mouse models with impaired liver function ${ }^{6}$.

1. Mitchell, C. \& Willenbring, H. A reproducible and well-tolerated method for 2/3 partial hepatectomy in mice. Nat. Protoc. 3, 1167-1170 (2008).

2. Tubbs, J.T. et al. Effects of buprenorphine, meloxicam, and flunixin meglumine as postoperative analgesia in mice. J. Am. Assoc. Lab. Anim. Sci. 50, 185-191 (2011).

3. Caro, A.C., Hankenson, F.C. \& Marx, J.0. Comparison of thermoregulatory devices used during anesthesia of C57BL/6 mice and correlations between body temperature and physiologic parameters. J. Am. Assoc. Lab. Anim. Sci. 52, 577-583 (2013).

4. Grant, G.J., Piskoun, B., Lin, A. \& Bansinath, M. An in vivo method for the quantitative evaluation of local anesthetics. J. Pharmacol. Toxicol. Methods 43, 69-72 (2000).

5. Matsumiya, L.C. et al. Using the mouse grimace scale to reevaluate the efficacy of postoperative analgesics in laboratory mice. J. Am. Assoc. Lab. Anim. Sci. 51, 42-49 (2012).

6. Elkader, A. \& Sproule, B. Buprenorphine: clinical pharmacokinetics in the treatment of opioid dependence. Clin. Pharmacokinet. 44, 661-680 (2005). 